\title{
Growth as a monitor of nutritional status
}

\section{By J. M. Tanner, Department of Growth and Development, Institute of Child Health, University of London}

The title of this paper carefully fails to distinguish between monitoring the growth of specific individual children and monitoring the growth (in height, weight and other anthropometric measurements) of populations and subpopulations. The distinction has no value in principle, for populations are merely the sum of the individuals who compose them. But from a practical point of view, the distinction is a very necessary one. It enshrines, to a large extent, operational approaches and professional demarcations. Nutritionists traditionally study populations of children; doctors, individual children. The human auxologist is by profession the person who endeavours to hold both approaches to growth simultaneously in focus. However, lest your vision become blurred by the effort of convergence I shall discuss the two monitoring problems separately; first and very briefly, that regarding individuals, and second, in slightly more depth, that regarding populations.

\section{Monitoring growth in individuals}

It is not necessary to argue that a child slows down in growth if for any reason he becomes undernourished. It is necessary, perhaps, to point out that when a human auxologist talks of 'growth' without further qualification, he is thinking of growth in height. Weight he regards as a thoroughly unsatisfactory measurement, a hotch-potch of different tissues in varying proportions, in a sense the equivalent of the pulped brains of yesterday's developmental enzymologists. Weight has its uses, certainly, but unless it is allied with measurements of the skeleton, the muscles and the adipose organ, it can be very seriously misleading, even in animal work (for example, see Williams, Tanner \& Hughes, 1974).

Since the first thing that happens in the undernourished child is a slowing down of growth, the relevant thing to monitor is growth velocity. Centile standards for velocity of height and weight were first introduced in 1966 (Tanner, Whitehouse \& Takaishi, 1966). There are various technical problems associated with their construction and use; they relate to specific (usually whole-year) periods of time since the range of variation is greater in shorter periods and less in larger ones, partly due to seasonal variation in growth rate; and they are constructed so that the centiles represent accurately the velocity of individuals who have the peak of their adolescent growth spurt (Tanner, 1962) at the average age for peaking. In a newer version of the standards (Tanner \& Whitehouse, 1976), based on the same 


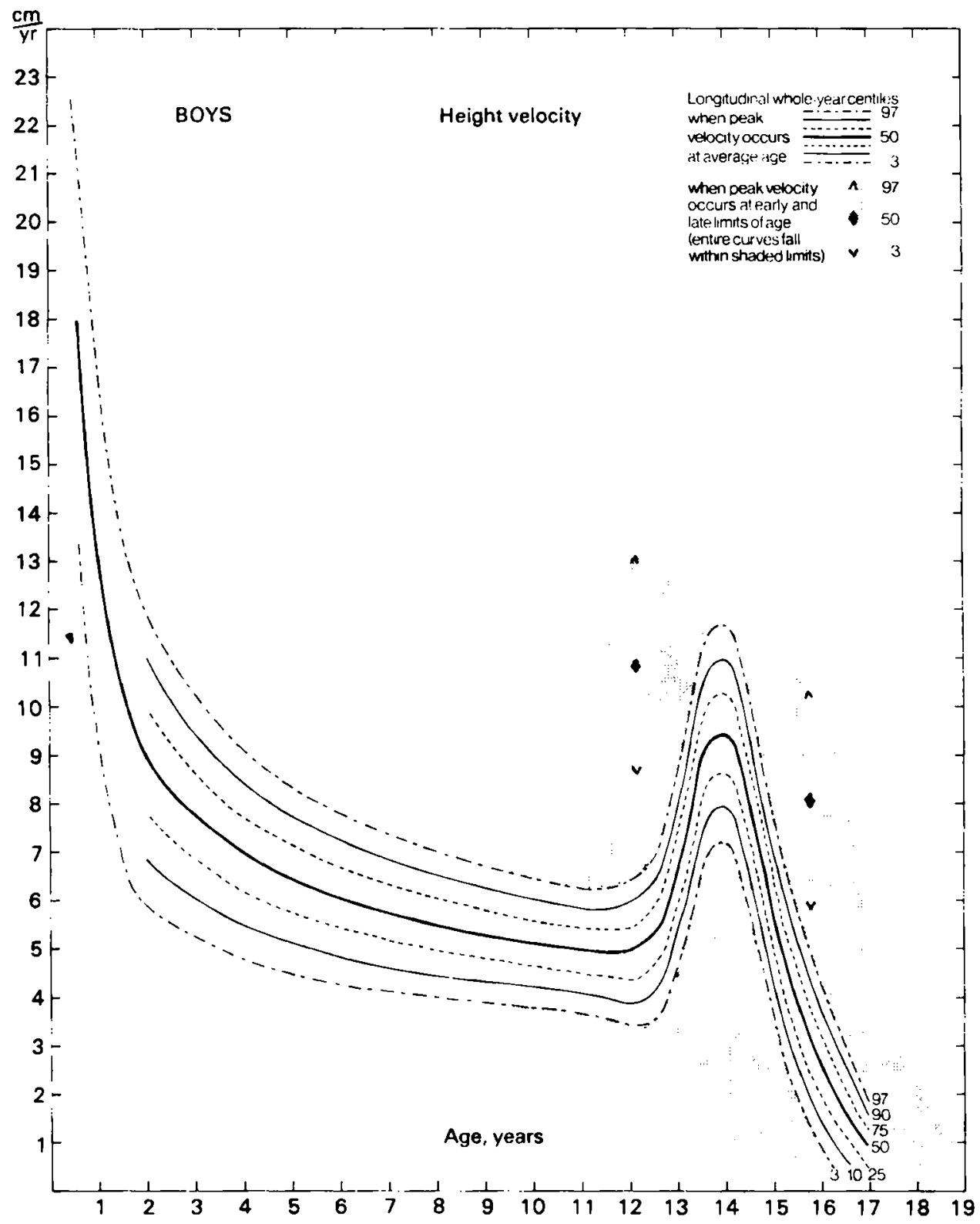

Fig. I. Height velocity standards for boys (from Tanner \& Whitehouse, 1976).

data, centiles for early and late maturing children have been incorporated over adolescence, giving normal limits for advancement or delay in growth pattern, and allowing for the fact that the peak of the height spurt is higher in earlier-maturing and lower in later-maturing children (Fig. I). These charts are the chief instrument for monitoring individuals. The effect of undernutrition is picked up much earlier this way than by 'distance' charts of the height for age or weight for age type, in 
which the child's position is affected by all his previous history, and especially by the size of his parents.

Undernutrition may be indicated first by a reduction in weight velocity, though the converse is not true; reduction in weight velocity may be a sign of better health and nutrition even in childhood. Reduction in height velocity in a previously wellgrowing child is often a sign of undernutrition in children in developed, industrialized countries, and in children of the rich in many underdeveloped ones. Reduced height velocity does not always indicate undernutrition, though it always indicates some disorder. Indeed, in my view, height velocity is the best general monitor of health that we have, and a good deal would be gained by introducing accurate serial measurements throughout childhood into modern general practice, or, failing that, the school medical service. There is a lot of old evidence, not all anecdotal, that attendance at unsympathetic (mostly boarding) schools may slow down growth (Allan, 1937; Friend, 1935; Friend \& Bransby, 1947; Widdowson \& McCance, I944) and there is Elsie Widdowson's (195I) famous experience with the cross-over (and cross) Sister in the otherwise matched orphanages in Germany in 1946. R. H. Whitehouse and I have recently noted a marked slowing of growth during the first term in a boys' boarding school, followed by catch-up and stabilization later; and also what seemed to be a considerable perturbation of growth and the pattern of pubertal development in some girls in boarding schools. It is clear from the experience of many paediatric endocrinologists working in Growth Disorder Clinics that even small amounts of cortisol in excess of the ordinary may slow down growth. This is one possible mechanism for the effects of school or social stress; inhibition of growth hormone secretion is another. Though we must be careful not to return to the days when errors from inefficient measurements were elevated to general principles of human growth, let alone indicators of an individual's progress, nevertheless 'partial' and 'transient' growth-hormone deficiency are now respectable if somewhat circular and double-eged (if that is possible) phrases. Inhibition of growth hormone secretion in response to psychological trauma was described by Powell, Brasel \& Blizzard (1967). In my own clinic we have had a few similar and striking cases; removal to another environment is promptly followed by a classical catch-up, that is, a phase in which growth velocity exceeds the limits of normal velocity for the child's age (Prader, Tanner \& Von Harnack, 1963). These children have very bizarre eating patterns but are not usually undernourished; they have the above-average skinfolds almost invariably seen in growth hormone deficiency.

\section{Monitoring growth in populations}

We turn now to the question of whether growth of height, weight and other measurements reflects the nutrition of a population, and, if so, how it may best be used as a monitoring device. We are now using the word 'growth' in a slightly different way, for actually we mean size at a given age, not growth (which standing alone should mean growth velocity). 


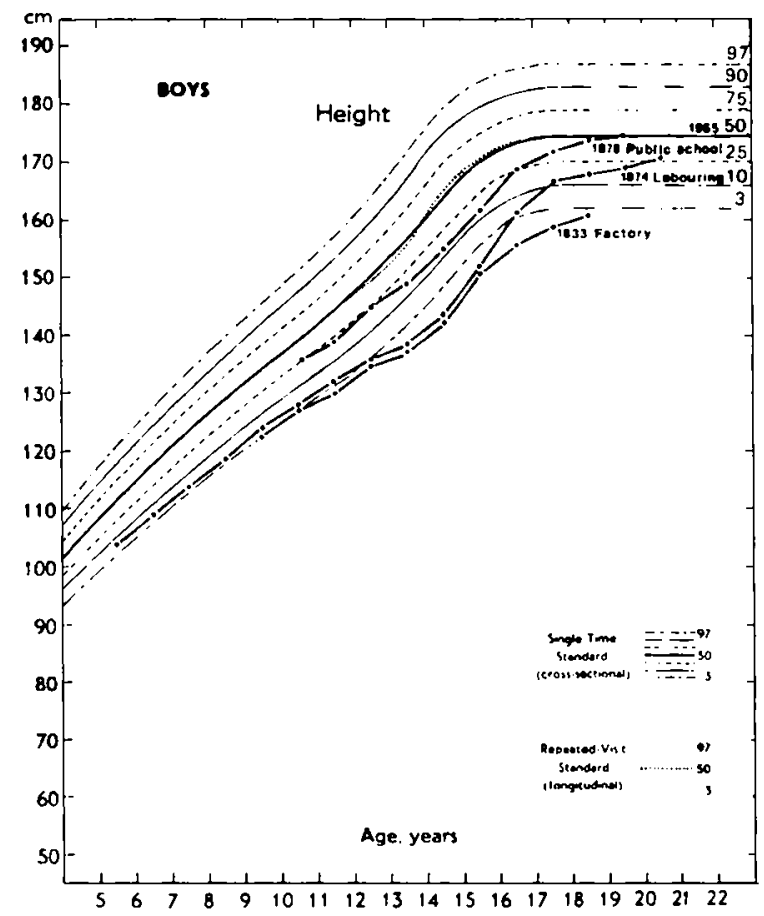

Fig. 2. Secular trend and social class differences in growth in UK, 1830-1960 (from Tanner, 1962).

There are two sorts of evidence from which we may infer that mean heights in a population reflect the average nutritional status of that population. The first relates to the secular trend, the second to the effects of social class and sibling number. The secular trend towards greater height at all ages, including adulthood, and also towards earlier maturity, is a well-known phenomenon (Tanner, 1966, 1968). Fig. 2 illustrates the rather scanty UK data. Detailed study in those countries for which good data exist shows that the trend has not been continuous and constant during the last 150 years, but varying from period to period, and even occasionally reversing. A good case can be made out in favour of the view that the trend follows the nutritional situation in the country concerned. This is true both of the trend in near-adult height of conscripts (van Wieringen, 1972, on Dutch material) and the trend towards earlier menarche (Brundtland \& Wallöe, 1976, in Norway). There is evidence that in certain well-off (even exotic) subpopulations, such as that constituted by men whose fathers, grandfathers and great-grandfathers as well as themselves had all attended Harvard University, the trend has stopped. In the best study of a whole (though only urban) population, of towns in Sweden, the trend was still visible between $193^{8}$ and 1968 (Fig. 3), but was much less then than in earlier years (Ljung, Bergsten-Brucefors $\&$ Lindgren, 1974). The trend in weight was actually reversed in girls from 1938 to 1968 , with the introduction of the slimmer Swede. Boys did not show this feature; which emphasizes my earlier remarks about weight as an inefficient monitor. 


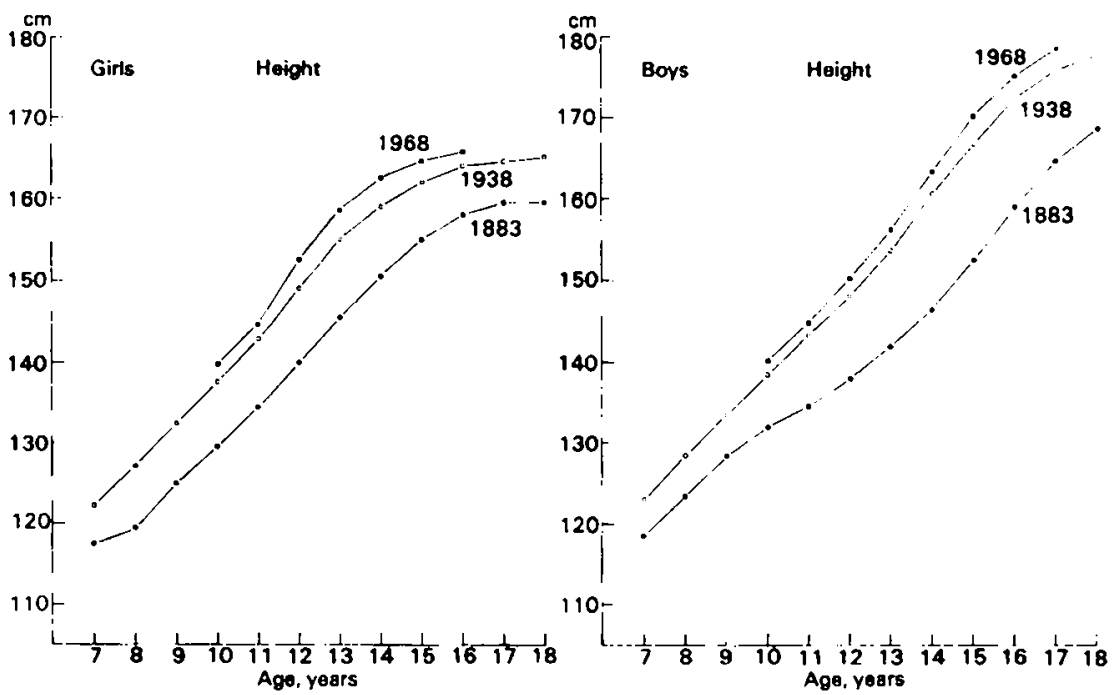

Fig. 3. Secular trend in girls' heights in Sweden (from Ljung et al. 1974).

Secondly, there are considerable differences in height at all ages, including adulthood, between children born to fathers working in different occupations, grouped into a number of socio-economic classes by a rather insensitive Registrar-General many years ago. Furthermore, within each occupational group the larger the number of siblings there are in the household, the shorter the children. Goldstein's (197r) excellent analysis of the National Child Development Survey sample of all children born in the first week of March 1958 shows these effects to be considerable at seven years of age (Fig. 4) and of similar magnitude at age eleven

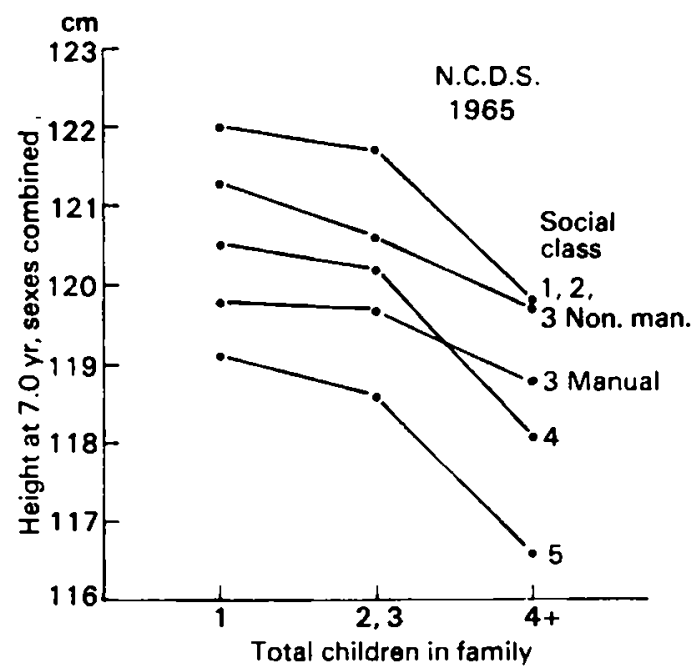

Fig. 4. The relation of height of seven-year-olds with father's occupation and number of siblings in family. National Child Development Survey. Based on results of Goldstein (1971). 
(Goldstein \& Peckham, 1976). Such occupational class differences ('intellectuals' and 'workers' in East European translated terminology) are a universal finding, to which the sole exception is furnished by the most recent Swedish data of Lindgren (1976). Here the occupational class differences have disappeared, and at just the same time as the trend in height of conscripts ceased. It seems likely that Sweden is the first country in which the great majority of the population is in an optimal state of height growth. In industrialized countries, be it noted, weight for height is greater in the less well-off classes than in the well-to-do (Eveleth \& Tanner, 1976). In underdeveloped countries the reverse is the case.

The age of menarche also is affected by occupational class and sibling number. Roberts, Danskin \& Chinn (1975) have shown that in the north of England at present all the differences between occupational classes disappear when the number of siblings is held constant between them. This is not yet the case for height at given age in the UK.

We may summarize these findings, then, by saying that there is good evidence that the heights of children at given ages, including adulthood, reflect, in most countries, something we may call nutritional status. Age at menarche, or at other pubertal transition points, does the same. But we have to remember that the whole concept of 'nutrition' is an abstraction from a much more complex reality, which includes parasites, maternal behaviour, the distribution of family income, the energy cost of older siblings, even the happiness and security of the child. So we are really discussing not nutrition but micro-ecology and not the monitoring of nutritional status, but of health itself.

Finally, we turn to the question of how such monitoring of growth (hence nutrition, hence health) of a population should be done. First we need good defined samples of the population (or the subpopulation at risk) investigated at repeated intervals. Until the Great Milk Robbery no such samples had been collected in this country (for work on this scale needs government involvement and even action). At present, under the auspices of the Committee on Medical Aspects of Food Policy (COMA), surveys are in progress which will rectify this situation for the 1970's and for longer if the scientific and medical community can persuade the Department of Health and Social Security that sensibly spaced continuous monitoring, as practised most outstandingly in Cuba (full methodological details in Jordan, Ruben, Hernandez, Bebelagua, Tanner \& Goldstein, 1975) and also in Holland and the USA, is a useful activity. The current surveys, set in motion to answer the very difficult question of whether withdrawal of free school milk adversely affected the growth of certain sections of the population, use a mixture of cross-sectional and longitudinal techniques. Height, weight, skinfolds and arm and calf circumferences are taken.

For more routine monitoring, especially in developing countries with lack of skilled personnel, a small group convened by WHO has recommended the use simply of two indices, height for given age and weight for given height (Buzina, Keller, Nichaman, Tanner \& Waterlow, 1977). In countries where age is known, the first index poses no particular problems except of training and equipment. The 
means of subpopulations believed to be at risk can be compared with those of welloff subpopulations. At each age height is distributed in a nearly Gaussian fashion and comparisons are straightforward, always provided that great care is taken to find the errors in instrument readings, transcriptions, etc., which bedevil any large series of results (see Jordan et al. 1975).

Weight for height is much trickier. First there is the question whether pooling between ages is permissible. This involves comparisons of distributions both as regards means and variances. Firstly, we have to ask whether the mean weight of a six-year-old of height $120 \mathrm{~cm}$ is the same as the mean weight of a seven-year-old of $120 \mathrm{~cm}$. Secondly, even supposing this is indeed the case, are the $3^{\text {rd }}$ and $97^{\text {th }}$ centile weights of six-year-olds of heights, say, I I $^{-125} \mathrm{~cm}$ the same as the $3^{\text {rd }}$ and 97 th centile weights of seven-year-olds of heights $115-120 \mathrm{~cm}$ ? Only if these two conditions are met can ages be legitimately pooled. Van Wieringen's (1972) Dutch findings indicate that no great error is introduced by pooling ages 1.0 to 9.9 years but that outside this range pooling introduces serious bias. Nutritionists and doctors in developing countries have always wanted an index which is independent of age, simply because ages tend to be unknown (though not always unknowable).

There is also the problem of the distribution of weight for height. In developed countries this is non-Gaussian. If the population is fat enough log weight approaches normality, but if not, it overcorrects. It seems unsatisfactory to have different transformations for different countries; but equally so to use tests of unknown bias. The problem is still unsolved.

\section{Summary}

I. Methods of monitoring growth of individuals in a population, and average growth in height and other measurements of populations or subpopulations must be distinguished.

2. Individual monitoring of nutritional status should be by growth velocity charts, for height, chiefly, and weight, if interpreted correctly. Growth velocity may be reduced by psychological stress; it monitors a total micro-ecological situation, not just a nutritional one.

3. Population monitoring requires defined and repeated samples. The secular trend and the differences in height for age and in age at menarche related to occupational class and number of siblings reflect nutritional differences, but only as part of the same micro-ecology. Height for age and weight-for-height-irrespectiveof-age have been recommended as monitors, especially for populations in developing countries. The latter poses methodological problems and is probably only legitimate between the ages of 1.0 and 9.9 years.

\section{REFERENCES}

Allan, J. (1937). Lancet i, 674 .

Brundtland, G. H. \& Wallöe, L. (1976). Ann. Hum. Biol. In the Press.

Buzina, R., Keller, W., Nichaman, M., Tanner, J. M. \& Waterlow, J. (1977). Bull. Wld Hlth Org. In the Press. 
Eveleth, P. B. \& Tanner, J. M. (1976). Worldwide variation in Human Growth. IBP Series. London and Cambridge: Cambridge University Press.

Friend, G. E. (1935). The schoolboy, his nutrition and development. Cambridge: Heffer.

Friend, G. E. \& Bransby, E. R. (1947). Lancet ii, 677.

Goldstein, H. (1971). Hum. Biol. 43, 92.

Goldstein, H. \& Peckham, C. (1976). Symp. Soc. Stud. Hum. Biol. 15, 81 .

Jordan, J., Ruben, M., Hernandez, J., Bebelagua, A., Tanner, J. M. \& Goldstein, H. (1975). Ann. Hum. Biol. 2, 153.

Lindgren, G. (1976). Ann. Hum. Biol. In the Press.

Ljung, B. O., Bergsten-Brucefors, A. \& Lindgren, G. (1974). Ann. Hum. Biol. 1, 245.

Powell, G. F., Brasel, J. A. \& Blizzard, R. M. (1967). New Engl. Y. Med. 276, 1271.

Prader, A., Tanner, J. M. \& Von Harnack, G. A. (1963). F. Pediat. 62, 646.

Roberts, D. F., Danskin, M. J. $8 x$ Chinn, S. (1975). Acta paediat. scand. 64, 84.

Tanner, J. M. (1962). Growth at Adolescence. 2nd Edition. Oxford: Blackwell Scientific Publications.

Tanner, J. M. (1966). Tijdschr. soc. Geneesk. 44, 524.

Tanner, J. M. (1968). Scient. Am. 2 18, 21.

Tanner, J. M. \& Whitehouse, R. H. (1976). Archs. Dis. Childh. 51, 170.

Tanner, J. M., Whitehouse, R. H. \& Takaishi, M. (1966a). Archs Dis. Childh. 41, 454.

Tanner, J. M., Whitehouse, R. H. \& Takaishi, M. (1966b). Archs Dis. Childh. 41, 613.

Van Wieringen, J. C. (1972). Seculaire groeiverschuiving. I. Length en gewicht surveys $1964-1966$ in Nederland in historisch perspectief. 2. Samenvatting in het Engels tabellen en figuren.

Widdowson, E. M. (1951). Lancet i, 1316.

Widdowson, E. M. \& McCance, R. A. (1944). Lancet ii, 152.

Williams, J. P. G., Tanner, J. M. \& Hughes, P. C. R. (1974). Paediat. Res. 8, 149. 